\title{
Breves representações da escola na literatura brasileira do final do século XIX
}

\section{Brief representations of the school in Brazilian literature of the end of $19^{\text {th }}$ century}

\begin{abstract}
A história da literatura, guardiã dos clássicos, dominou os estudos literários no século XIX e, sobretudo em nosso país, passou do âmbito especializado para o universo da escola.
\end{abstract}

(Regina Zilberman, 2001)

Maria Eneida Matos da Rosa'

\begin{abstract}
Os regimes populares exigem que esqueçamos, e portanto classificam os livros como luxos supérfluos; os regimes totalitários exigem que não pensemos, e portanto proíbem, ameaçam e censuram; ambos, de um modo geral, exigem que nos tornemos estúpidos e que aceitemos nossa degradação docilmente, e, portanto, estimulam o consumo de mingau.
\end{abstract}

(Alberto Manguel, 2006)

\section{Resumo}

O presente artigo pretende verificar como a escola é representada nas obras literárias do final do século XIX. Será possível observar, nesse esboço genealógico, uma tentativa de construção da história da literatura, tendo como um dos seus personagens principais a escola. A literatura documenta em suas narrativas, numa espécie de metalinguagem, o papel da escola e, sobretudo, as conotações negativas que fazem parte do campo semântico desse local de ensino e que se ampliaram na contemporaneidade, revelando o fracasso dessa instituição através do cotejo entre ensino, leitura e literatura no Brasil do final do século XIX.

Palavras-chave: Literatura. Ensino. Escola punitiva no século XIX.

\begin{abstract}
This article aims to verify how the school is represented in literary works of the end of the $19^{\text {th }}$ century. It will be possible to observe, in this genealogical sketch, an attempt to build a history of literature, having the school as one of its main characters. The literature documents in its narratives, in a kind of metalanguage, the role of the school and specially the negative connotations that make part of the semantic field of this educational establishment and which have increased nowadays, revealing the failure of this institution through the comparison between teaching, reading and literature in Brazil at the end of $19^{\text {th }}$ century.
\end{abstract}

Keywords: Literature. Education. Punitive school in $19^{\text {th }}$ century.

1 Doutora em Teoria da Literatura pela Pontifícia Universidade Católica do Rio Grande do Sul (PUCRS) e professora do Centro Universitário de Brasília (UniCEUB). 


\section{Introdução}

O presente artigo pretende verificar como a escola é representada nas obras literárias do final do século XIX. Será possível observar, nesse esboço genealógico, uma tentativa de construção da história da literatura, tendo como um dos seus personagens principais a escola. A literatura documenta em suas narrativas, numa espécie de metalinguagem, o papel da escola e, sobretudo, as conotações negativas que fazem parte do campo semântico desse local de ensino e que se ampliaram na contemporaneidade, revelando o fracasso dessa instituição através do cotejo entre ensino, leitura e literatura no Brasil do final do século XIX.

Quando nasceu na Antiguidade grega, a literatura não tinha esse nome. Chamava-se poesia e existia para entreter a nobreza. Narrativas como Ilíada e Odisséia, ao contarem as origens da nação helênica e explicarem a diferença entre deuses e homens, ditavam para a população as normas de comportamento da sociedade.

Iniciava-se, pois, o gérmen da propensão educadora da poesia, também observada nos mitos, que antecipavam os paradigmas de ação a serem acatados pela comunidade primitiva, na condição de requisito para a sobrevivência do grupo. Entre os gregos, a poesia herdou a propriedade pedagógica dos mitos. Passaram-se muitos séculos até a literatura adotar o nome que atualmente a identifica.

Mais tarde, sobretudo na Renascença, a relação entre a poesia e o ouvinte perdeu o caráter comunitário e público, tendendo para o particular e o íntimo, enfraquecendo a influência do Estado e se colocando numa posição mais discreta. A situação se modificou, de fato, depois que a educação passou a ser gerenciada pela escola.

Integrada ao currículo escolar, a literatura não podia perder sua força educativa, no entanto, sua natureza foi alterada: deixou de ter finalidade intelectual e ética e adquiriu cunho linguístico, unindo-se assim a um desejo de expressão nacional.

Isso significa afirmar que a literatura, ao se aliar ao desejo de construir uma história e uma identidade nacional, acabou por se confundir e fazer parte da urdidura da maioria das histórias da literatura. Quer dizer, a literatura mudou seu status e confundiu-se com a expressão de uma língua nacional numa tentativa de afirmação e formação de uma identidade.
Com efeito, o caráter educativo ganhou configurações mais amplas, porque o ensino de literatura reforçou o tema constante nas histórias da literatura e no sistema literário em construção. Desse modo, o local onde se vive constitui uma unidade independente, com propriedades, tais como a língua e a cultura, que a definem e personalizam. Tais convicções não pareciam apresentar fundamento pedagógico e sim ideológico.

No que se refere ao Brasil, Letícia Malard assevera que o ensino da literatura é o mais antigo do Brasil. Ele começou nos primeiros colégios fundados aqui pelos padres jesuítas que se transferiram para as terras do Novo Mundo em missão de catequese. A finalidade da literatura nesses colégios correspondia à propagação do ensino jesuítico, isto é, formar catequistas para converter os indígenas e formar letrados capazes de fazer belos poemas e sermões. Todavia, o ensino de literatura mostrava-se distante da realidade:

O estudo limitava-se aos clássicos gregos e latinos, eram lidos para supervalorizar a beleza do mundo antigo, as qualidades do texto literário e do conteúdo moral da poesia, decorada e declamada. Servia para enfeite da memória. Este ensino distanciado da realidade permanecerá sempre como característica da educação brasileira. (MALARD, 1985, p. 8).

Nesse primeiro momento, a literatura se aproximava de um cunho ideológico e religioso de viés catequético mais sistemático. O Caramuru (1781), de Santa Rita Durão, por exemplo, ilustra essa situação, uma vez que se configura na exposição do projeto educacional da Companhia de Jesus. De acordo com as palavras de Lajolo \& Zilberman (2002), Durão converte Diogo Alvares Correia num pedagogo exemplar que, conforme reforçam as estudiosas, "impressionado com a ferocidade dos índios, antropófagos e sanguinários, dispõe-se a educá-los, resgatando a suposta humanidade dos índios" (Lajolo \& Zilberman, 2002, p. 20):

\footnotetext{
Daí, portanto, senhor potente impulso, Com que possa entoar sonoro o metro Da brasílica gente o invicto pulso, Que aumenta tanto império ao vosso cetro; E, enquanto o povo do Brasil convulso Em nova lira canto, em novo plectro, Fazei que fidelíssimo se veja $\mathrm{O}$ vosso trono em propagar se a igreja
}

(Canto I, VIII).

Da nova Lusitânia o vasto espaço Ia a povoar Diogo, a quem bisonho Chama o Brasil, temendo o forte braço, 
Horrível filho do trovão medonho,

Quando do abismo por cortar lhe o passo

Essa fúria saiu como suponho,

A quem do inferno o paganismo aluno,

Dando o império das águas, fez Netuno

(Canto I, IX).

Desse modo, Alfredo Bosi (2001) afirma que o índio, tratado como outro, isto é, como objeto de colonização e catequese, perde a autenticidade étnica e regride ao marco zero de espanto (quando antropófago) ou a exemplo de edificação (quando religioso).

A literatura como disciplina, conforme observa Malard, foi incluída no currículo dos colégios através da reforma educacional de Benjamin Constant (1889). Surgiu paralela ao fato de que a literatura francesa se transformou em disciplina escolar na França, país que vinha influenciando nossa cultura desde a independência política de 1822. Essa influência se mostrou muito presente ao longo dos anos e a literatura brasileira ficou marcada pela presença da leitura de pequenos trechos de obras, memorização de obras e autores, pequenas biografias e listagem das obras dos escritores. Tal metodologia parece persistir até hoje, constatando o fato de que a disciplina sempre andou distante da realidade e exageradamente historiográfica.

Apesar de o presente artigo tratar de uma espécie de percurso acerca da literatura como disciplina, o que se pretende aqui é constatar na própria literatura brasileira discussões acerca do ensino de modo que seja possível observar uma espécie de construção da história da literatura, tendo como um dos seus personagens principais a escola. A literatura documenta em suas narrativas o papel da escola, aspecto relevante para mostrar como se faz o cotejo entre ensino, leitura e literatura.

\section{Literatura versus escola: imagens de punição e entretenimento}

É comum encontrarmos nas obras literárias que tratam da escola, a visão desse espaço de ensino, como um lugar de punição. Em Memórias de um sargento de milícias (1978), de Manuel Antônio de Almeida, por exemplo, o narrador registra que o protagonista Leonardo frequenta a escola por obrigação.

A figura do professor, nessa obra, também parece explicar uma parcela do desinteresse demonstrado por Leonardo:
Era este um homem todo em proporções infinitesimais, baixinho, magrinho, de carinha estreita e chupada, excessivamente calvo, tinha pretensões a latinista e dava bolos nos discípulos por dá cá aquela palha. Por isso era um dos mais acreditados na cidade. [...] e o menor erro que algum dos discípulos cometia não lhe escapava no meio de todo o barulho; fazia parar o canto, chamava o infeliz, emendava cantando o erro cometido, e cascava-lhe pelo menos seis puxados bolos. Era o regente da orquestra ensinando a marcar o compasso (ALMEIDA, 1978, p. 56).

Lajolo e Zilberman (2002, p. 11) destacam que

da parte do professor, ter pretensões a latinista, usar e abusar da palmatória são cauções de credibilidade e renome: as letras clássicas e os castigos corporais dão-se as mãos na constituição de um padrão intelectual e pedagógico.

A pedagogia da escola punitiva persiste ao longo do século XIX e, por seu turno, é constantemente evocada em passagens da literatura brasileira. Machado de Assis fornece alguns desses exemplos em Memórias póstumas de Brás Cubas (1881) e no Conto de escola (1884), onde reaparece a temível imagem da palmatória como método educativo.

A normalista, de Adolfo Caminha (1983), também faz a descrição da personagem João Mata, que parece aproximar-se da imagem do professor "respeitado/temido" pela sociedade descrita em Memórias de um Sargento de Milícias:

João da Mata era um sujeito esgrouvinhado, esguio e alto, carão magro de tísico, com uma cor hepática denunciando vícios de sangue, pouco cabelo, óculos escuros através dos quais boliam dois olhos miúdos e vesgos. Usava pêra e bigode ralo caindo sobre os beiços, tesos como fios de arame; a testa ampla confundia-se com a meia calva reluzente. Falava depressa, com um sotaque abemolado, gesticulando bruscamente, e, quando ria, punha em evidência a medonha dentuça postiça. Noutros tempos fora mestreescola no sertão da província, de onde se mudara para a capital por conveniências particulares. Era então simplesmente o professor Gadelha, o terror dos estudantes de gramática. O sertão foi-lhe aborrecendo; estava cansado de ensinar a meninos, era preciso fazer pela vida noutro meio mais vasto onde as suas qualidades, boas ou más, fossem aquilatadas com justiça (ALMEIDA, 1978, p. 10).

Todavia, Adolfo Caminha (2011, p. 19) ilustra outros aspectos do contexto escolar mencionado. As mulheres eram educadas em conventos e, por isso, recebiam uma educação religiosa. Afora isso revela o espírito pervertido de João da Mata, padrinho de Maria do Carmo, 
que tinha interesse por sua sobrinha e gostaria de vê-la educada aos moldes europeus e transformada numa perfeita mulher do lar:

Também fora professor, olé! e sabia muito bem
o que isso era um coito de patifarias. Queria a
educação como nos colégios da Europa, segun-
do vira em certo pedagogista, onde as meninas
desenvolvem-se física e moralmente como a ra-
paziada de calças, com uma rapidez admirável,
tornando-se por fim excelentes mães de família,
perfeitas donas-de-casa, sem a intervenção in-
quisitorial da Irmã de Caridade. Não compreen-
dia (tacanhez de espírito embora) como pudes-
se instruir-se na prática indispensável da vida
social uma criatura educada a toques de sineta,
no silêncio e na sensaboria de uma casa con-
ventual, entre paredes sombrias, com quadros
alegóricos das almas do purgatório e das penas
do inferno; com o mais lamentável desprezo de
todas as prescrições higiênicas, sem ar nem luz,
rezando noite e dia ora pro nobis, ora pro nobis...

O trecho trata de uma representação popular comum acerca da educação das moças, que parece se assemelhar à obra A escola de mulheres, de Jean Baptiste Moliére, que apresenta um tutor que também nutre desejos em relação a sua protegida: “Assim como uma noviça/ De cor no convento deve saber o seu ofício,/ Entrando no casamento deve-o igualmente" (III, 2).

A obra vai além, uma vez que, na voz da personagem João da Mata, tece uma denúncia ao comportamento dos padres que mantinham afilhadas como amantes e as educavam conforme as suas intenções:

\begin{abstract}
João da Mata detestava a padraria. Dava-se apenas com um padre, o cônego Feitosa, porque, dizia ele, era um sacerdote sem hipocrisia, um padre como ele entendia que deviam ser todos os padres: asseado, inimigo da batina, com afilhadas em casa... E por que não? Os padres são fisicamente (e sublinhava a palavra), anatomicamente, fisiologicamente homens como os outros: têm coração, órgãos sexuais, nervos como os outros homens (CAMINHA, 2011, p. 19).
\end{abstract}

Sem contar a menção aos romances considerados proibidos na época, que tratavam de temas como o adultério, mas que, na verdade, revelavam o caráter escapista proporcionado pela literatura:

\begin{abstract}
Uma noite o padrinho quase a surpreende no quarto, deitada, com o romance aberto, à luz duma vela. Porque ela só lia $O$ Primo Basílio à noite, no seu misterioso quartinho do meio da casa pegado à sala de jantar. Que regalo todas aquelas cenas da vida burguesa! (CAMINHA, 2011, p. 34).
\end{abstract}

Para ilustrar essa cena de leitura, há que se considerar as palavras de Alberto Manguel (2006, p. 35) quan- do diz que "algo na relação entre um leitor e um livro é reconhecido como sábio e frutífero, mas também como desdenhosamente exclusivo e excludente". A imagem dessa relação acaba por revelar uma privacidade impenetrável, ou ainda, conforme Manguel, olhos egoístas e ação dissimulada e singular. $\mathrm{O}$ estudioso afirma ainda que o

medo popular do que um leitor possa fazer entre as páginas de um livro é semelhante ao medo intemporal que os homens têm do que as mulheres possam fazer em lugares secretos de seus corpos, e do que as bruxas e os alquimistas possam fazer em segredo, atrás de portas trancadas (MANGUEL, 2006, p. 36).

Outra obra que retrata o universo da escola ou ainda da temática do ensino é O Ateneu, de Raul Pompéia (1981). Como se sabe, esse local é descrito mais uma vez como um espaço de punições e abusos. Aliás, a narrativa revela um ambiente totalmente hostil e degradante, marcado pela figura autoritária e temida do diretor Aristarco.

A escola, nesse caso, consegue aliar literatura e escrita como forma de punição, como é possível constatar no trecho a seguir:

Franco era silencioso, como arreceado de todos, tristonho, de uma melancolia parente da imbecilidade; tinha acessos refreados de raiva, queixas que não sabia formular. Os livros, causa primeira de seus desgostos, faziam-lhe horror. A necessidade de escrever por castigo promovera nele a habilidade dos galés: adquirira um desembaraço pasmoso na faina de encher de garranchos páginas e páginas. Esta interminável escrita fizera-lhe calos aos cantos das unhas [...] (POMPÉIA, 1981, p. 108).

Interessante destacar, contudo, a presença da literatura como uma espécie de alento para os momentos mais difíceis. Existem dois locais na escola que servem de fuga e entretenimento para os alunos. Trata-se da biblioteca e do Grêmio Literário; espaços onde as crianças aproveitam para fazer leituras prazerosas, quer dizer, escolhidas por eles e não obrigatórias e, ao mesmo tempo, fugir da violência que compõe a atmosfera da escola. Configura-se, pois num espaço próprio de evasão, mas, ao mesmo tempo, de criação.

É no espaço Grêmio Literário Amor ao Saber, que os alunos entram em contato maior com os livros de forma mais prazerosa e sem obrigações escolares, bem como põem em prática suas ideias num periódico:

$\mathrm{Na}$ interessante publicação apareciam quadrinhas místicas do Ribas e sonetos lúbricos do Sanches. Barreto publicara meditações, espécie 
de harpa do crente em prosa arrebentada. O rodapé-romance era uma imitação d'O Guarani, emplumada de vocábulos indígenas e assinada - Aimbiré (POMPÉIA, 1981, p. 143).

Para Ricardo Piglia (2006, p. 29), “a leitura é ao mesmo tempo a construção de um universo e um refúgio diante da hostilidade do mundo". Desse modo, as palavras de Piglia, se coadunam com o pensamento de Zilberman (2001a, p. 38) quando diz que "capacitando o ser humano a agir com liberdade, ainda que mediado pela fantasia e pelo imaginário, a leitura sinaliza o perigo para sociedades ou indivíduos totalitários".

Se os alunos, contudo, elegem os seus livros preferidos que os reportam para lugares distintos e distantes de sua realidade, há, de outro lado, a malfadada leitura obrigatória. O Ateneu, escrito no século XIX, já trata desse tema que persiste até hoje, corroborado pelas listas obrigatórias de livros indicados para o vestibular. Os alunos eram obrigados a ler Os Lusíadas e, por esse motivo, reclamavam tanto da imposição quanto do próprio livro, que não lhes parecia prazeroso em sua leitura.

Quer dizer, a partir desse ponto exposto na obra, é possível observarmos que o referido assunto esbarra em algo constante nas escolas hoje em dia: a eleição de leituras obrigatórias. Costuma-se fazer todos os anos uma seleção de obras para o vestibular. Todavia, também somos marcados por seleções ou listas diariamente, haja vista a presença de eleições dos livros mais lidos, que movem leitores de última hora, bem como outras seleções feitas por estudiosos da literatura nas suas histórias da literatura.

Nesse aspecto, Márcia Abreu (2006, p. 110) assevera que a:

Grande Literatura convive com outras literaturas, de menor prestígio, mas de grande apelo. Entre um e outro conjunto de livros (consagrados e não consagrados), a escola tende a aproximar-se da opinião de intelectuais e esquecer - ou pior, estigmatizar o gosto das pessoas comuns.

Os escritores em suas obras também produzem uma espécie de seleção de seus pares. N'O Ateneu, na abertura solene do Grêmio, Dr. Cláudio, o palestrante, escolhe o que para ele, seria o melhor de nossa literatura no seu tempo. Elenca os seguintes nomes e movimentos literários:

a galhofa de Gregório de Matos e Antônio José, a unção de Sousa Caldas e São Carlos, a influência de Magalhães, os ensaios do romance nacional, a glória de Gonçalves Dias e José de Alencar. (POMPÉIA, 1981, p. 151).

Todavia, nesse caso, a intenção do autor se refere ao fato de este se colocar no sistema literário consagrado. Assim, Raul Pompéia se insere no mesmo patamar de seus pares.

Um dos maiores problemas relacionados ao ensino da literatura e à própria formação do leitor diz respeito ao fato de que, ao se desejar impor uma visão histórica, converte-se a história em mera cronologia e se enumeram nomes de obras, autores, estilos, períodos e escolas, criando-se, assim, um processo interminável de mera reprodução.

Machado de Assis também pintou um quadro acerca da educação em algumas narrativas, a começar por Memórias póstumas de Brás Cubas (1881), que já começa caracterizada como enfadonha pela protagonista, que também se revela uma personagem que aprecia fazer diabruras. Todavia, apesar das peraltices de Brás Cubas na infância, de certo modo, não deixa de tratar de suas amarguras e os aspectos negativos recorrentes acerca da escola:

Tinha amarguras, esse tempo; tinha os ralhos, os castigos, as lições árduas e longas, e pouco mais, mui pouco e mui leve. Só era pesada a palmatória, e ainda assim...Ó palmatória, terror dos meus dias pueris, tu que foste o compelle entrare com que um velho mestre, ossudo e calvo me incutiu no cérebro o alfabeto, a prosódia, sintaxe, e o que mais ele sabia, lenta palmatória, tão praguejada dos modernos, quem me dera ter ficado sob o teu jugo, com a minha alma imberbe, as minhas ignorâncias [...]. (MACHADO DE ASSIS, 2010, p. 23).

Mas "Conto de escola" publicado na obra Várias estórias, já antecipa a preocupação do autor com a corrupção da sociedade, comumente revelada em suas obras, e reforça ainda mais o aspecto punitivo ao tratar das semelhanças entre as imagens autoritárias do pai e do professor.

Nesse conto, o autor parte do espaço da escola para o espaço da liberdade para ilustrar as cores negativas que vigoram nesse local de ensino. Pilar, protagonista da narrativa, mostra, desde o início, o seu descontentamento em frequentar a escola e, através da janela, vislumbra um cenário mais agradável e acolhedor:

Com franqueza, estava arrependido de ter vindo. Agora que ficava preso, ardia por andar lá fora, e recapitulava o campo e o morro, pensava nos outros meninos vadios, o Chico Telha, 
o Américo, o Carlos das Escadinhas, a fina flor do bairro e do gênero humano. Para cúmulo do desespero, vi através das vidraças da escola, no claro azul do céu, por cima do morro do Livramento, um papagaio de papel, alto e largo, preso de uma corda imensa, que bojava no ar, uma cousa soberba. (MACHADO DE ASSIS, 2011, p. 25).

Para piorar o quadro descrito pela personagem, Pilar reclama estar na escola, "sentado, pernas unidas, com o livro de leitura e a gramática nos joelhos". Tal cena parece reforçar a visão negativa acerca da escola e suas temidas listas de leituras obrigatórias, isso sem contar a presença da malfadada gramática também aludida no trecho.

Cenário negativo que persiste também em Memórias póstumas de Brás Cubas, quando Brás-menino descreve a escola como uma espécie de prisão, preferindo estar na rua com os companheiros de "diabruras":

\footnotetext{
Unamos agora os pés e demos um salto por cima da escola, a enfadonha escola, onde aprendi a ler, escrever, contar, dar cacholetas, e ir fazer diabruras, ora nos morros, ora nas praias, onde quer que fosse propício e ocioso. (MACHADO DE ASSIS, 2010, p. 82)
}

Afora tais descrições, persiste a temida palmatória "com seus cinco olhos do diabo", bem como a própria figura do professor Policarpo, aliada a sua imagem autoritária de pai de outro menino, Raimundo. A imagem do professor também parece se assemelhar à figura do pai de Pilar, que somente o colocara na escola por aspirar a uma grande posição comercial ao filho e imaginava vê-lo "com os elementos mercantis, ler, escrever e contar, para me meter de caixeiro. Citava nomes de capitalistas que tinham começado no balcão".

\section{Considerações finais}

Apesar de se exemplificar através da própria literatura o caráter educativo autoritário e punitivo, há que se destacar a crise do ensino da literatura, principalmente. De um modo geral, constata-se que os alunos não gostam de ler ou gostam de ler obras que não fazem parte da eleição do cânone. Denuncia-se ainda a falta de eficiência do professor de literatura, tendo em vista que os alunos não aprendem (apreendem) o conteúdo, desconhecem a gramática, não escrevem corretamente, de tal modo que a literatura deixou para trás o seu papel educativo e forma- dor. Nessa perspectiva, a literatura também perdeu a eficácia pedagógica esperada pela burguesia. Mas, cumpre destacar que, no Brasil, isso é resultado do próprio projeto educacional elaborado para um conjunto da sociedade que procurou usar a escola como formadora de mão-de-obra para a industrialização que se mostrava acelerada.

Mesmo que exista um distanciamento entre a escola descrita no século XIX e o modelo existente na atualidade, é possível constatar que alguns aspectos perduram, entre eles a obrigatoriedade da leitura de obras eleitas pelo cânone. O resultado desse controle através dos anos recaiu, sobretudo, no fato de que a leitura está longe de ser algo prazeroso.

Nesse sentido, trazer para a sala de aula textos escritos por mulheres (sobre mulheres), negros, homossexuais, marginalizados, enfim toda a sorte de temas e gêneros que fazem parte do cotidiano de muitas pessoas que afirmam não gostar da literatura seria uma possível solução. Solução proposta, aliás, por Márcia Abreu e que parece se coadunar com a intenção dos Estudos Culturais, corrente teórica nascida na comunhão entre teorias estruturalistas e marxistas, que se propõe estudar a cultura das minorias ou de temas considerados irrelevantes para o academicismo retrógrado e amante das histórias da literatura com seus roteiros e modelos prontos, tecidos através de interesses e paixões elitistas.

Com efeito, recorre-se às palavras de Roberto Scarpit quando diz que é preciso dessacralizar a literatura, liberá-la de seus tabus sociais, abrindo caminho para o segredo de sua potência. Então talvez seja possível refazer não a história da literatura, mas a história dos homens em sociedade, segundo o diálogo dos criadores de palavras, mitos e ideias com seus contemporâneos e com a posteridade, que agora chamamos literatura.

\section{Referências}

ABREU, Márcia. Cultura letrada: literatura e leitura. São Paulo: Unesp, 2006.

ALMEIDA, Manuel Antônio de. Memórias de um sargento de milícias. Rio de Janeiro: Livros Técnicos e Científicos, 1978.

ASSIS, Machado de. Memórias póstumas de Brás Cubas. Porto Alegre: L\&PM, 2010. 
ASSIS, Machado de. Conto de escola. Disponível em: $<$ http://www.dominiopublico.gov.br/download/texto/ ua000191.pdf $>$. Acesso em: 10 jul. 2011.

BOSI, Alfredo. História concisa da literatura brasileira. São Paulo: Cultrix, 2001.

CAMINHA, Adolfo. A normalista. Disponível em: $<$ http://www.dominiopublico.gov.br/download/texto/ bn000001.pdf. $>$. Acesso em: 12 ago. 2011.

LAJOLO, Marisa; ZILBERMAN, Regina. A leitura rarefeita: leitura e livro no Brasil. São Paulo: Ática, 2002.

LAJOLO, Marisa; ZILBERMAN, Regina. O preço da leitura: leis e números por detrás das letras. São Paulo: Ática, 2002.

MALARD, Letícia. Ensino e literatura no $2^{\circ}$ grau: problemas e perspectivas. Porto Alegre: Mercado Aberto, 1985.
MANGUEL, Alberto. Uma história da leitura. São Paulo: Companhia das Letras, 2006.

MOLIÈRE. O Tartufo. Escola de mulheres. O burguês fidalgo. São Paulo: Abril Cultural, 1980.

PIGLIA, Ricardo. O último leitor. São Paulo: Companhia das Letras, 2006.

POMPÉIA, Raul. O Ateneu: crônica de saudades. Rio de Janeiro: Civilização Brasileira, 1981. v. 2.

ZILBERMAN, Regina. A leitura e o ensino da literatura. São Paulo: Contexto, 1988.

ZILBERMAN, Regina. Fim do livro, fim dos leitores? São Paulo: Senac, 2001a.

ZILBERMAN, Regina. Argh, os clássicos! Argh? Jornal Zero Hora, Caderno Cultura, p. 4-5, 26 de maio de 2001. 


\section{Para publicar na revista}

Universitas Humanas,

acesse $o$ endereço eletrônico www.publicacoesacademicas.uniceub.br. Observe as normas de publicação, para facilitar e agilizar o trabalho de edição. 